\title{
Low intensity pulsed ultrasound for fractures of the tibial shaft.
}

\author{
(9) (1) $\Theta$ OPEN ACCESS \\ We now have sound evidence that it doesn't work
}

\section{$\mathrm{X} L$ Griffin associate professor of trauma surgery}

Oxford Trauma, Nuffield Department of Orthopaedics Rheumatology and Musculoskeletal Sciences, University of Oxford, Kadoorie Centre, John Radcliffe Hospital, Oxford OX3 9DU, UK

\begin{abstract}
The key characteristic of a clinical researcher is probably the determination to deliver high quality studies despite all the inevitable bumps along the road. As well as the difficulties around funding and maintaining large collaborations that can deliver high impact multicentre studies, there are also more worrying challenges that threaten the robustness of the science. Some are widely recognised, such as publication bias, others are less overt; the reluctance of sponsors to complete some industry funded studies if the results aren't going their way and the distorting effect of regulatory policies on study design, such as regulatory demand for placebo controlled designs rather than more useful comparative research.
\end{abstract}

In a linked paper, Busse and colleagues (doi:10.1136/bmj.i5351) report findings from a trial of low intensity pulsed ultrasound (LIPUS) in tibial fracture healing. ${ }^{1}$ They are to be congratulated both for the rigour of the study and their perseverance in bringing it to completion.

Fractures of the tibial shaft are major injuries. They heal slowly, often to such a degree that further surgery is required to stimulate or accelerate the healing processes. These complications are debilitating for patients and expensive for health systems. Consequently, tibial fractures have been a prime target for numerous interventions designed to aid recovery, including electromagnetic stimulation, drug treatments such as bone morphogenetic proteins, and low intensity pulsed ultrasound.

Previous randomised trials investigating the effectiveness of ultrasound treatment have had inconclusive results.

Meta-analyses, which have attempted to pool these trial data, have consistently characterised a research topic comprising a few small trials reporting large positive effects. ${ }^{23}$ In the language of GRADE, ${ }^{4}$ further research is likely to change our confidence in and size of the effect.

Busse and colleagues report a randomised trial comparing self administered ultrasound with sham ultrasound in 501 US adults with fractures of the tibial shaft treated by internal fixation with an intramedullary nail. The co-primary outcome was time to fracture healing over one year, assessed with plain radiographs; other outcomes included important functional and quality of life measures reported by patients. The authors found no significant differences between groups for any outcome. They conclude that ultrasound does not accelerate healing of tibial fractures or improve functional recovery.

On the face of it, this is a clear report of the clinical ineffectiveness of a commonly used treatment. Behind the report of the trial, however, is the story of these investigators' determination to bring their study to a successful conclusion.

The initial design focused around a functional primary outcome reported by patients. This protocol was first developed and submitted to a funding body in 2006. Subsequently, the US Food and Drug Administration (FDA) asked the authors to switch their primary outcome to radiographic healing, an outcome also preferred by the industry sponsor. In the end, radiographic healing was added as a co-primary outcome. Assessments of radiographic healing are notoriously unreliable and are, at best, only a proxy for successful outcomes as reported by patients.

Further complications occurred when the industry sponsor conducted an unplanned interim analysis in late 2012, which prompted a decision in March 2013 to terminate the study early on the grounds of futility. This meant that 73 participants were unable to fully complete the follow-up schedule. Three years of negotiation followed between the sponsor and the investigators - which the authors say included requests for multiple unplanned subgroup analyses - until finally we are able to read the full report of this study in a peer reviewed journal.

Fortunately for patients, clinicians, and future clinical guideline groups the results were eventually clear, despite the influence of outside agencies. These authors report important patient-centred outcomes with a precise estimate, showing that low intensity pulsed ultrasound is of no benefit to adults with 
tibial fractures treated with an intramedullary nail. It is time for us to make good use of their determination and abandon this ineffective treatment.

Competing interests: I have read and understood the BMJ Group policy on declaration of interests and declare the following interests: None.

Provenance and peer review: Commissioned; not peer reviewed.

$1 \quad$ TRUST Investigators Writing GroupBusse JW, Bhandari M, Einhorn TA, et al. Re-evaluation of low intensity pulsed ultrasound in treatment of tibial fractures (TRUST): randomized clinical trial. BMJ 2016:355:15351.
2 Griffin XL, Parsons N, Costa ML, Metcalfe D. Ultrasound and shockwave therapy for acute fractures in adults. Cochrane Database Syst Rev 2014;6:CD008579. doi:10.1002/ 14651858.CD008579.pub3. pmid:24956457.

3 Busse JW, Kaur J, Mollon B, et al. Low intensity pulsed ultrasonography for fractures: systematic review of randomised controlled trials. BMJ 2009;338:b351. doi:10.1136/bmj. b351 pmid:19251751.

4 GRADE working group. www.gradeworkinggroup.org.

Published by the BMJ Publishing Group Limited. For permission to use (where not already granted under a licence) please go to http://group.bmj.com/group/rights-licensing/ permissions

This is an Open Access article distributed in accordance with the Creative Commons Attribution Non Commercial (CC BY-NC 3.0) license, which permits others to distribute, remix, adapt, build upon this work non-commercially, and license their derivative works on different terms, provided the original work is properly cited and the use is non-commercial. See: http://creativecommons.org/licenses/by-nc/3.0/. 